\title{
Perinatal Morbidity and Mortality in the Regional University Teaching Hospital of Borgou (BENIN) In 2013
}

\author{
d'Almeida $\mathrm{M}^{1}$, Noudamadjo $\mathrm{A}^{2}$, Obossou $\mathrm{AAA}^{2^{*}}$, Agossou $\mathrm{J}^{2}$, Adedemy $\mathrm{JD}^{2}$ and Abogbo $\mathrm{D}^{2}$ \\ ${ }^{1}$ Department of Mother and Child, Faculty of Health Sciences, Cotonou, University of Abomey-Calavi, Republic of Benin \\ ${ }^{2}$ Department of Mother and Child, Faculty of Medicine, University of Parakou, Republic of Benin
}

*Corresponding author: Obossou AAA, Gynecologist \& Obstetrician, Faculty of Medicine, University of Parakou, Republic of Benin, Tel :(229) $95853279 / 97067852$; E-mail: awadefr2000@yahoo.fr

Received date: April 04, 2016; Accepted date: May 08, 2016; Published date: May 15, 2016

Copyright: ( $) 2016$ d'Almeida M, et al. This is an open-access article distributed under the terms of the Creative Commons Attribution License, which permits unrestricted use, distribution, and reproduction in any medium, provided the original author and source are credited.

\begin{abstract}
Introduction: Perinatal mortality is still high in the developing countries, with a significant proportion for early neonatal mortality. Its reduction depends on identification of causes in view of priority actions to achieve the fourth Millennium Development Goal.
\end{abstract}

Objective: Describe perinatal morbidity and mortality in the major hospital facility of North-Benin.

Settings and method: It was a cross-sectional, descriptive and prospective study conducted over the period from March 1 through August 31, 2013 in the Mother \& Child Unit of the Borgou Regional University Hospital (CHUD-Borgou) located in Parakou i.e. in the North-Benin.

Findings: Perinatal mortality rate was $153.55 \%$ still birth rate $87.39 \%$ and early neonatal mortality rate $66.16 \%$. Fetal suffering (48.21\%), morbidity associated with fetal membranes, through premature rupture of the membranes $(60.58 \%)$ and neonatal morbidity through neonatal infections $(26.32 \%)$ were the leading causes of fetal morbidity. Fetal suffering $(31.43 \%)$ was the leading cause of late fetal deaths; and neonatal infections (33.96\%), prematurity $(28.30 \%)$ and perinatal asphyxia (18.87\%) were the leading causes of early neonatal deaths.

Conclusion: Perinatal mortality is high in the Borgou Regional University Teaching Hospital (CHUD). Its reduction requires a holistic approach based on new-born care policy.

Keywords: Perinatal mortality; Perinatal morbidity; Perinatal asphyxia; Benin

\section{Introduction}

Perinatal mortality rate (PMR) is a reliable indicator of the quality of obstetrical and paediatric care [1]. According to the 2009 UNICEF Report, neonatal mortality declines more slowly than mortality of children under five years of age [1]. In fact, out of the 130 million annual births, 4 million die during the first four weeks of their life. The $3 / 4$ of those deaths occurs during the first week [2]. About two thirds of those deaths occur in Africa and in Southeast Asia against one third for the rest of the world, thus showing the gap existing between rich and poor countries [3]. In Benin, a study performed in the National University Teaching Hospital of Cotonou (CNHU- Cotonou) in 2009 reported a $122 \%$ perinatal mortality (PM) [4]. CHD-Borgou is the major hospital facility in North-Benin and perinatal mortality which is the lower indicator of a country's obstetrical and health status is little known there; thus the interest of this research work which aimed to describe perinatal morbidity and mortality in the major hospital facility in the North-Benin.

\section{Setting and Methods}

The study was carried out in the Mother and Child Unit of the Borgou Regional Hospital (CHD-Borgou), located in Parakou in the North-Benin. CHD-Borgou is a second-level referral center in the health pyramid/system of Benin. It has become a university teaching hospital since the University of Parakou was founded in 2002. This investigative work is a prospective and descriptive study conducted during the period from March 1 to August 31, 2013. Sample minimum size was calculated using the Schwartz formula $\mathrm{N}=(\mathrm{Za})^{2} \times \mathrm{pq} / \mathrm{i}^{2}$; where $\mathrm{N}$ is the expected minimum sample $(\mathrm{Z} \alpha)$ : $\mathrm{Z}$-score of normal distribution, equal to 1.96 for $a=5 \%, p$ the perinatal mortality identified in CNHU-Cotonou in 2009 [4] which is equal to $12.2 \%$, $\mathrm{q}$ the complementary event of probability i.e. 1-p: $87.8 \%$ and $\mathrm{i}$ the accepted margin of error i.e. 5\%. According to that formula, sample minimum size was 165 .

\section{The study involved:}

- all the live-born infants followed up during the first seven days of life and whose perinatal outcome was known, delivered at the end of at least 22 weeks of amenorrhea or weighing at least $500 \mathrm{~g}$ when due date was not known, after parents' informed consent.

- All the still-born delivered from pregnancy of at least 22 weeks of amenorrhea and/or weighing at least $500 \mathrm{~g}$ in the delivery ward of the CHD-Borgou maternity, after parents' oral informed consent. 
Citation: d'Almeida M, Noudamadjo A, Obossou AAA, Agossou J, Adedemy JD, et al. (2016) Perinatal Morbidity and Mortality in the Regional University Teaching Hospital of Borgou (BENIN) In 2013. Clinics Mother Child Health 13: 244. doi:10.4172/2090-7214.1000244

Page 2 of 5

-The live-born infants whose condition was unknown on the $7^{\text {th }}$ day of life (new-born's lost to follow up) were excluded.

Sampling without replacement and consecutive sampling were used.

Data were collected using a form of survey based on interview with the mother, and by also using mother's obstetrical record and newborn medical record if the latter was hospitalized in the CHD-Borgou neonatal care unit.

The study variables were socio-demographic characteristics of mothers and products of conception, mothers' clinical characteristics, new-born's ' characteristics, perinatal morbidity, fetal morbidity, morbidity associated with the fetal membranes, early neonatal morbidity and perinatal mortality.

Definitions used for variables related to perinatal morbidity and mortality

Live births: products of conception of at least 22 weeks of amenorrhea (WA) who showed any sign of life after delivery [5]

Stillbirth: products of conception of at least 22 WA who did not present with any sign of life after delivery [5]

Early neonatal mortality : death occurred within the seven days after birth of a product of conception of at least 22 WA [5]

Clinically-apparent neonatal infection: presence of any physical or biological sign (positive CRP or leukopenia lower than $5000 / \mathrm{mm}^{3}$ or hyperleukocytosis higher than $25000 / \mathrm{mm}^{3}$ or thrombocytopenia lower than $100000 / \mathrm{mm}^{3}$, or pleiocytosis higher than 10 elements $/ \mathrm{mm}^{3}$ )

Perinatal asphyxia: condition of any new-born with an APGAR score lower than 4 to 1 minute of life or lower than 7 to 5 minutes of life

Prematurity: childbirth on or after 22 WA but before 37 WA

Intrauterine growth retardation (IUGR): birth weight below the 10th percentile of intrauterine growth curves

Respiratory distress: association of at least the following 2 signs (bradypnea, tachypnea, signs of struggling to breathe, central cyanosis)

Congenital malformation: congenital morphological anomaly of an organ or part of the body which is detectable or occurs from birth.
Neonatal jaundice: yellow discoloration of skin and mucous membranes due to a hyperbilirubinemia higher or equal to $40 \mathrm{mg} / \mathrm{l}$

Anemia : hemoglobin level lower than $14 \mathrm{~g} / \mathrm{l}$

Congenital malaria: positive thick blood smear, regardless of newborn clinical condition

Hemorrhagic syndrome: spontaneous bleeding in the new-born

Neurological disorder: clinical condition characterized by an altered consciousness or chronic seizures

Macrosomia: birth weight above the 90th percentile of intrauterine growth curves.

To identify gestational age, chronologilcal due date or ultrasound due date (early ultrasound) were used. In the absence of chronologilcal or ultrasound due date, weight of the product of conception higher or equal to $500 \mathrm{~g}$ was used to include statistical units.

Data were recorded and processed using EPIINFO software 7.1.1.14 version. To describe them, ratios and averages (with standard deviation) were respectively calculated for qualitative and quantitative variables.

Word processing and design of graphics were performed using Word and Excel software.

For ethical reasons, the anonymity of new-born's and of their mothers was respected. Besides, confidentiality of the data collected was observed and inclusion of each statistical unit was previously submitted to mother for oral informed consent.

\section{Results}

During the study, 801 new-borns were involved they were born of 765 pregnancies, including 728 mono-fetal (95.16\%), 36 twin pregnancies $(4.70 \%)$ and one triplet pregnancy $(0.13 \%)$.

\section{Sociodemographic characteristics of mothers and products of conception}

Table 1 shows the distribution of mothers according to their sociodemographic characteristics.

\begin{tabular}{|c|c|c|}
\hline Characteristics & Numbers & Percentage (\%) \\
\hline \multicolumn{3}{|l|}{ Maternal age } \\
\hline Lower or equal to 18 years & 43 & 5.62 \\
\hline Between 19 and 34 years & 626 & 81.83 \\
\hline Higher or equal to 35 years & 96 & 12.55 \\
\hline \multicolumn{3}{|l|}{ Living environment of mothers } \\
\hline Urban & 618 & 80.78 \\
\hline Rural & 147 & 19.22 \\
\hline \multicolumn{3}{|l|}{ Educational status of mothers } \\
\hline Non-educated & 311 & 40.66 \\
\hline Primary school & 185 & 24.18 \\
\hline
\end{tabular}


Citation: d'Almeida M, Noudamadjo A, Obossou AAA, Agossou J, Adedemy JD, et al. (2016) Perinatal Morbidity and Mortality in the Regional University Teaching Hospital of Borgou (BENIN) In 2013. Clinics Mother Child Health 13: 244. doi:10.4172/2090-7214.1000244

Page 3 of 5

\begin{tabular}{|l|l|l|}
\hline Secondary school & 198 & 25.88 \\
\hline University & 71 & 9.28 \\
\hline
\end{tabular}

Table 1: Distribution of mothers according to their socio-demographic characteristics.

\section{Clinical characteristics of mothers $(\mathrm{N}=765)$}

Mothers were primigravida, paucigravida and multigravida in respectively $25.79 \%, 39.13 \%$ and $35.08 \%$ of the cases.

Nulliparous and primiparous represented respectively $19.11 \%$ and $19.37 \%$ of the cases. Mothers were pauciparous and multiparous in respectively $4 \%$ and $35.08 \%$ of the cases.

Twenty-four percent (24\%) of the mothers had an abortion history.

One still-born history and one neonatal death history had been found out in respectively $7 \%$ and $7.72 \%$ of the mothers.

Concerning antenatal care (ANC), $4.97 \%$ of the mothers had not benefitted from any, 36.13\% received between 1 and 3 ANC and $58.90 \%$ attended at least $4 \mathrm{ANC}$.

Mothers reported to the maternity for delivery by their own in $50 \%$ of the cases. They were referred from a peripheral health facility in $50 \%$ of the cases.

The main reasons for referral were dystocia (21.07\%), acute fetal suffering (14.97\%), reno- vascular syndrome (12.44\%), premature rupture of the membranes (PRM), uterine scar, dystocia presentation for $7.81 \%$ each.
Mothers had normal pelvis in $69.5 \%$ of the cases and abnormal in $29.5 \%$ of the cases.

A pathological rupture of the membranes (premature, early or prolonged) had been noted in $37.88 \%$ of the cases.

\section{Clinical characteristics of new-born's $(\mathrm{N}=801)$}

Table 2 shows the distribution of new-born's delivered in CHDBorgou from March 1 through August 31, 2013 according to pregnancy due date.

Vaginal birth was registered in 416 new-born's (51.93\%). In 3.74\% of the cases (30 subjects), birth weight was between 500 and $999 \mathrm{~g}$; it was between 1000 and $2499 \mathrm{~g}$ in $21.10 \%$ of the cases (169 subjects) and between 2500 and $4000 \mathrm{~g}$ in $74.66 \%$ of the cases (598 subjects). Four new-born's $(0.50 \%)$ had a birth weight higher than $4000 \mathrm{~g}$.

New-borns were male in $54.3 \%$ of the cases (435 subjects) and female in $45.69 \%$ of the cases ( 366 subjects), i.e. a 1.18 sex-ratio.

Among the live 731 new-born's (92.26\% of 801 ), perinatal asphyxia was diagnosed in 97 subjects (13.26\%); APGAR score was lower than 4 to 1 minute of life in 8 live new-born's $(1.09 \%)$ and lower than 7 to 5 minutes in $89(12.17 \%)$.

\begin{tabular}{|l|l|l|}
\hline Due date (WA) & Number & Percentage (\%) \\
\hline $22-27$ & 15 & 1.87 \\
\hline $28-32$ & 39 & 4.87 \\
\hline $33-36$ & 77 & 9.61 \\
\hline $37-42$ & 478 & 59.68 \\
\hline 43 and more & 8 & 1.00 \\
\hline Inaccurate & 184 & 22.97 \\
\hline Total & 801 & 100.00 \\
\hline
\end{tabular}

Table 2: Distribution of new-born's delivered in CHD-Borgou from March 1to August 31, 2013 according to pregnancy due date.

\section{Perinatal morbidity}

Fetal morbidity $(\mathrm{N}=801)$ : Fetal morbidity had been noted in 392 subjects (48.93\%). The abnormalities observed were acute fetal suffering in 189 subjects $(48,21 \%)$, faulty presentation in 101 subjects (25.75\%), multiple pregnancies in 36 subjects $(9.18 \%)$, and threat of preterm birth in 27 subjects (6.89\%). Cephalopelvic disproportion, passing the due date, abnormal volume of amniotic fluid, and blighted infection were noted in respectively $4.86 \%, 2.04 \%, 2.04 \%$ and $1.02 \%$ of the cases.

Morbidity associated with the fetal membranes $(\mathrm{N}=801)$ : Abnormalities of fetal membranes were identified in 137 fetuses (17.10\%); these were premature rupture of the membranes $(60.58 \%)$, coils of funis $(18.98 \%)$, placenta previa $(10.95 \%)$ and cord prolapse, in $9.49 \%$ of the cases.

Early neonatal morbidity ( $\mathrm{N}=801)$ : Four hundred thirty-seven newborn's $(54.55 \%)$ needed care in the neonatal care unit. The pathologies identified are listed in Table 3.

\begin{tabular}{|l|l|l|}
\hline Morbidity & $\begin{array}{l}\text { Number } \\
(\mathrm{n}=437)\end{array}$ & Percentage (\%) \\
\hline Clinically-apparent INN & 115 & 26.32 \\
\hline Perinatal asphyxia (PNA) & 97 & 22.2 \\
\hline Prematurity & 90 & 20.59 \\
\hline
\end{tabular}


Page 4 of 5

\begin{tabular}{|l|l|l|}
\hline Hypotrophy & 57 & 13.04 \\
\hline Respiratory distress (RD) & 18 & 4.12 \\
\hline Congenital malformations & 18 & 4.12 \\
\hline Jaundice & 16 & 3.66 \\
\hline Congenital malaria & 13 & 2.97 \\
\hline Anemia & 9 & 2.06 \\
\hline Hemorrhagic disease & 2 & 0.46 \\
\hline Neurological disorder & 2 & 0.46 \\
\hline
\end{tabular}

Table 3: Frequency of early neonatal morbidity in CHD-Borgou from March 1 to August 31, 2013.

Perinatal mortality $(\mathrm{N}=801)$ : During the study period, a total of 801 births were registered, including 731 live births. The number of perinatal deaths was 123 , including 70 late fetal deaths and 53 early neonatal deaths.

Late fetal mortality rate (number of late fetal deaths over total number of births) was $87.39 \%$. Early neonatal mortality rate (number of early neonatal deaths over total number of births) was $66.16 \%$. Perinatal mortality rate (number of perinatal deaths over total number of birth) was $153.55 \%$.

Out of 123 deaths registered, 41 occurred in the antenatal period (33.33\%), 29 in intrapartum (23.58\%), 7 during intensive care $(5.69 \%)$ and 46 after transfer to the neonatal care unit (37.40\%).

Figure 1 shows the distribution of early neonatal deaths according to period of occurrence. More than 2 deaths out of 5 occurred within the first 24 hours of life.

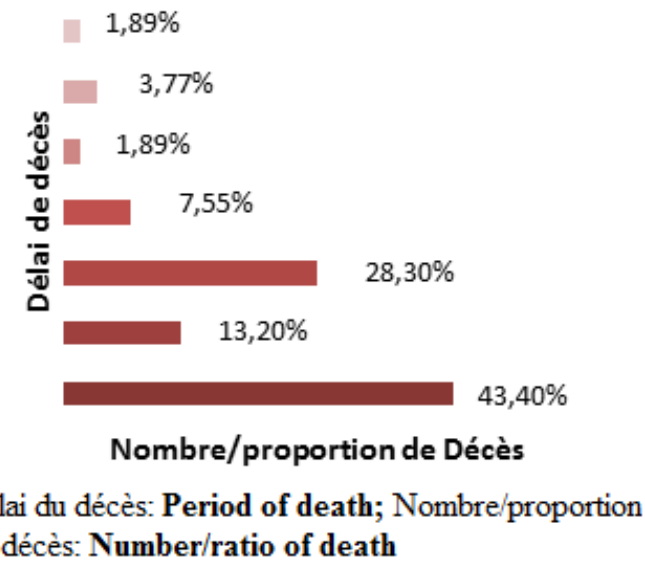

Figure 1: Distribution of early neonatal deaths according to their occurrence in the CHD- Borgou in $2013(\mathrm{~N}=53)$.

Causes of death: The most common causes of stillbirth $(\mathrm{N}=70)$ identified were acute fetal suffering in $31.43 \%$ of the cases, abruption placenta or uterine rupture in $17.14 \%$ of the cases and blighted infection in $10.00 \%$ of the cases. The other causes were placenta previa (5.71\%), funicular abnormalities $(4.29 \%)$ and dystocia (2.86\%). The causes were unknown in $28.57 \%$ of the cases.

The causes of early neonatal deaths $(\mathrm{N}=53)$ were neonatal infection in 18 cases $(33.96 \%)$, prematurity in 15 cases $(28.30 \%)$, perinatal asphyxia in 10 cases (18.87\%), respiratory distress in 8 cases $(15.09 \%)$ and multiple congenital malformation in 2 cases (3.78\%).

\section{Discussion}

\section{Mortality}

Perinatal mortality: Perinatal mortality rate in the CHUD-B in 2013 was $153.6 \%$. In the literature, a significant variability of perinatal mortality rate between countries is noted, with a big gap between developed countries and developing countries. In this respect, while French authors reported a perinatal mortality of $10.7 \%$, [6,7]. African authors such as Bayou et al. in Ethiopia in 2012 [8], Cissé et al. in Senegal in 2006 [9] and d'Almeida et al. in Benin in 2009 [4] reported respectively rates of $124 \%, 169.89 \%$ and $122.40 \%$. The high rate of $153.55 \%$ found out in this research work may be due to the conjunction of many factors. First, there is the agreed threshold of viability (gestational age higher or equal to 22 WA or birth weight higher or equal to 500g) to take into account the WHO recommendations [5]. Then, there is the recurring issue of lack of technical facilities and appliances in developing countries. Faced with that high rate, a proactive policy for new-born care proves to be necessary for reducing perinatal mortality.

Perinatal morbidity and causes of death: During the fetal period, the two most common morbidities identified were acute fetal suffering (AFS) and premature rupture of the membranes (PRM). Those abnormalities were identified by many African authors. In fact, Minko et al. in Gabon in 2004 [10], Nagalo et al. in Burkina Faso in 2013 [11] identified respectively $61.95 \%$ and $53.5 \%$ of PRM. Those common fetal morbidities raise the issue of good practices in obstetrics in a context of poverty where refocused antenatal care and good use of partograph to ensure labor monitoring may be very beneficial.

During the early neonatal period, neonatal infections (NNI), perinatal asphyxia and prematurity were the leading causes of morbidity. Those three morbid conditions which cause high numbers of neonatal deaths are reported by several African authors [9,11-14]. Their high proportion in neonatal mortality may be due to our context characterized by a lack of sanitation, health education, health workers' compliance with recommendations based on clinical evidence and good practice of neonatal intensive care.

Acute fetal suffering (AFS), placental abruption (PA) and blighted infection are the leading causes of fetal deaths. The significant proportion of AFS among the causes of fetal deaths highlights the early diagnosis issue through an efficient labor monitoring using partograph for rapid extraction of the fetus. In addition to that, there is lack of intensive care in the labor ward. These remarks were made by Traoré et al. in Mali in 2011 [15] and d'Almeida et al. in Benin in 2009.

The three main causes of death identified during the early neonatal period were neonatal infection, perinatal asphyxia and prematurity. These causes are the ones identified by other authors from the subregion such as Edmond et al. in Ghana in 2008, [16] Udo et al. in Nigeria in 2008 [17]. To fight efficiently against those three modifiable causes of neonatal death, particular prevention and management measures are required in our context where infant and child mortality is still affected by stagnant neonatal mortality. 
Citation: d'Almeida M, Noudamadjo A, Obossou AAA, Agossou J, Adedemy JD, et al. (2016) Perinatal Morbidity and Mortality in the Regional University Teaching Hospital of Borgou (BENIN) In 2013. Clinics Mother Child Health 13: 244. doi:10.4172/2090-7214.1000244

Page 5 of 5

\section{Conclusion}

This study which aimed to describe perinatal morbidity and mortality in the Borgou Regional University Teaching Hospital in 2013 has shown that about one out six new-born's died during the perinatal period. Moreover, it has pointed out the main causes of fetal death which are AFS and placental abruption. It has also identified the causes of early neonatal deaths which are neonatal infection, perinatal asphyxia and prematurity. In order to reduce that high perinatal mortality rate, it is necessary to review its associated factors in order to develop an appropriate new-born care policy.

\section{Acknowledgements}

The authors are particularly grateful to the parturient women who accepted to participate to this study. They also have special thoughts for the selected new-born's.

\section{References}

1. United Nations Children Fund (UNICEF) (2009) Report on the situation of children in the world: maternal and neonatal health. New York 2008.

2. Labie D (2005) The scandal of 4 million neonatal deaths every year: Results and possible actions. Medicine/Sciences 21: 768-767.

3. World Health Organization (WHO) (2012) Global health statistics, Geneva.

4. d'Almeida M, Bagnan L, Alihonou F, Lawson C, Lalya F et al. (2009) Perinatal mortality in the national university teaching hospital (CNHU) of Cotonou: Causes and associated factors. Le Bénin Medical 41: 33-36.

5. World Health Organization (2006) Reproductive Health Indicators: guidelines for their generation, interpretation and analysis for global monitoring, Geneve p 76 .

6. "Birth Safety-To be born together" a Health Network on New-born Care of the Pays de la Loire (France) (2011) Evaluation of child health and mortality Indicators, Paris 38: 1-46.
7. French Academy of Medicine (2010) Maternal mortality and perinatal mortality of children full-term infants in France.

8. Bayou G, Berhan Y (2012) Perinatal mortality and associated risk factors: A case control study (Ethiopia). Ethiop J Health Sci 22: 153-162.

9. Cisse CT, Yacoubou Y, Ndiaye O, Diop-Mbengue R, Moreau JC (2006) Progression of early neonatal mortality between 1994 and 2003 in the CHU of Dakar. J Gynécol Obstét Biol Reprod 35: 46-52.

10. Minko JL, Meye JF, Thiane EHO, Owono-Megniembo M, Makaya A (2004) Acute fetal suffering: experience of the neonatal care unit of the University Teaching Hospital of Libreville-Gabon. Méd d'Afr Noire 5104: $227-230$.

11. Nagalo N, Dao F, Tall FH, Yé D (2013) Morbidity and mortality of newborn's hospitalized over 10 years in the El Fateh-Suka Clinic (Ouagadougou, Burkina Faso). Pan Afr Med J 14: 153.

12. Bobossi-Serengbe G, Sana Deyamissi T, Diemer S, Gaudueille A, Gresenguet G, et al. (2004) Neonatal morbidity and mortality in the Pediatric Complex of Bangui (Central African Republic). Méd d'Afr Noire 5103: 159-63.

13. Mukhtar-Yola M, Iliyasu Z (2007) A review of neonatal morbidity and mortality in Aminu Kano Teaching Hospital, northern Nigeria. Trop Doct 37: 130-132.

14. Azoumah KD, Balaka B, Aboubakari AS, Matey K, Yolou A, et al. (2010) Neonatal morbidity and mortality in the CHU Kara (Togo). Med d'Afr Noire 5702: 109-12.

15. Traore B, Beye S, Kokaina C, Sacko D, Teguete I, et al. (2011) Perinatal mortality in the mother and child pole of Segou in Mali. Med. d'Afr. Noire 5804: 203-208.

16. Edmond KM, Quigley MA, Zandoh C, Danso S, Hurt C, et al. (2008) Aetiology of stillbirths and neonatal deaths in rural Ghana: implications for health programming in developing countries. Paediatr Perinat Epidemiol 22: 430-437.

17. Udo JJ, Anah MU, Ochigbo SO, Etuk IS, Eknanem AD (2008) Neonatal morbidity and mortality in Calabar; Nigeria: a hospital-based study. Niger J clin Pract 11: 285-289. 